\title{
Mechanical Properties of Ultra High Molecular Weight Polyethylene Obtained with Different Cocatalyst Systems
}

\author{
Galina Zamfirova, ${ }^{\dagger}$ José M. Pereña, Rosario Benavente, Ernesto PÉrez, \\ María L. CERRADA, and Emanuel NEDKOV* \\ Instituto de Ciencia y Tecnología de Polímeros (CSIC), Juan de la Cierva 3, 28006 Madrid, Spain \\ *Institute of Polymers, Bulgarian Academy of Sciences, 1113 Sofia, Bulgaria
}

(Received September 10, 2001; Accepted December 20, 2001)

\begin{abstract}
Three types of semicrystalline ultra high molecular weight polyethylene, obtained with amorphous $\mathrm{SiO}_{2}$-supported Ziegler-Natta catalyst systems modified by vanadium and titanium, have been studied by wide angle $\mathrm{X}$ Ray scattering, dynamic mechanical thermal analysis and microhardness methods. In all the cases a significant amount of monoclinic modification is observed, which is estimated to be of the order of $10 \%$. With increasing the degree of crystallinity and quantity of entanglements, storage modulus and $\alpha$ relaxation increase and $\gamma$ relaxation decreases. A weak $\beta$ relaxation occurs only in the sample obtained with vanadium catalytic systems. Microhardness measurements give the possibility of distinguishing the effect of crystallinity from the effect of entanglements: Vickers microhardness is sensitive predominately to crystalline phase, while total microhardness is sensitive also to the structural peculiarities in the amorphous phase.

KEY WORDS Ultrahigh Molecular Weight Polyethylene (UHMWPE) / Dynamic Mechanical Thermal Analysis (DMTA) / Wide-Angle X-Ray Diffraction (WAXS) / Microhardness /
\end{abstract}

Ultrahigh Molecular Weight Polyethylene (UHMWPE) $\left(\mathrm{M}>10^{6}\right)$ possesses excellent mechanical properties and some advantages over conventional polyolefins as a high level of durability, excellent creep characteristics and abrasion resistance. ${ }^{1-5}$ For this reason it is used in demanding applications such as artificial hip and knee joints, machine parts, fibres, polymer coating on metal surface, separators, acoustic diaphragms, etc.

It is established that this semicrystallyne polymer has a specific morphology. There are many reports concerning the structure of nascent ${ }^{6}$ and differently processed UHMWPE samples. ${ }^{3,7-9}$ The occurrence of polymorphism ${ }^{3,7,10-12}$ is characteristic for crystal part, the orthorhombic crystals lattice being the most typical. It was established that the crystal lamellae in both nascent and processed unoriented UHMWPE have similar dimensions, close to $20 \mathrm{~nm}$ on average. ${ }^{6}$ This thickness could be varied from $10 \mathrm{~nm}$ after necking ${ }^{13}$ up to $100 \mathrm{~nm}$ in highly oriented fibres. ${ }^{8}$ There are reported some cases where a part of the typical, stable and prevailing orthorhombic crystals could be transformed into a monoclinic or transient hexagonal phase. ${ }^{3,7-11,14,15}$ Thus, monoclinic crystals are observed in highly deformed samples (fibers) ${ }^{7-10}$ or in the samples crystallized under stress. ${ }^{16}$ Moreover, there are experimental results showing that polyethylene crystals transform from the stable orthorhombic crystal into a transient hexagonal phase, observed when the polymer is sub- jected to the action of fast electrons ${ }^{14}$ or at high pressure and temperature. ${ }^{3,15}$ Since the chain mobility is rather high in the hexagonal phase, sintering has been achieved via this transient phase. ${ }^{3}$

There were found reports concerning to the study of the amorphous phase by $\mathrm{NMR}^{8}$ and by positron annihilation lifetime spectroscopy. ${ }^{17}$ It was reported a 5\% of disordered all-trans interfacial material and/or tie molecules in addition to a $11 \%$ of mobile amorphous regions with diameters of $\sim 10 \mathrm{~nm}$, and a $1 \%$ of highly mobile segments, probably at void surfaces. ${ }^{8}$ Moreover, it was observed that pores of two different mean radii $\left(R_{3} \sim 1.8 \AA\right.$ and $\left.R_{4} \sim 3.3 \AA\right)$ exist in the amorphous areas of the UHMWPE samples. ${ }^{17}$

The aim of this work is to study the relationship between molecular structure and mechanical behavior of the three ultrahigh molecular weight polyethylenes synthesized by different catalyst systems using the dynamic mechanical measurements, microhardness and X-Ray scattering.

\section{EXPERIMENTAL}

\section{Materials}

Three types of semicrystalline UHMWPE, obtained with amorphous $\mathrm{SiO}_{2}$-supported Ziegler-Natta catalyst systems modified by vanadium (sample 1) and titanium (samples 2 and 3) have been studied. The difference between 2 and 3 catalyst systems are in the ratio of co-

†Permanent address: Higher Inst. of Transp. Eng. “T. Kableshkov”, Geo Milev str., 158. 1574 Sofia, Bulgaria. 
catalyst, which is reflected on their activity. The kind and the structure of catalyst system used, polymerization conditions and kinetics is described in. ${ }^{18,19}$ Table I shows the catalyst used and the molecular weight, $M_{\eta}$, determined viscometrically in decalin at $135^{\circ} \mathrm{C}$ and degree of crystallinity obtained from WAXS. Samples were prepared by pressing the polymer powder at $180^{\circ} \mathrm{C}$ and $10 \mathrm{MPa}$ during $10 \mathrm{~min}$ and then cooling to room temperature.

\section{WAXS Measurements}

WAXS studies were recorded at room temperature by means of an X-Ray diffractometer Siemens D-500 using $\mathrm{Cu}-K_{\alpha}$ radiation. The WAXS degree of crystallinity was calculated by the equation: $f_{\mathrm{X}-\mathrm{ray}}=A_{\mathrm{c}} /\left(A_{\mathrm{c}}+A_{\mathrm{a}}\right)$, where $A_{\mathrm{c}}$ is the area of the crystal peaks and $A_{a}$ is the area of the amorphous halo in the range $7^{\circ}-14^{\circ}(\theta)$ of the scattering angles.

\section{DMTA Measurements}

Dynamic mechanical measurements were carried out on a Polymer Laboratories MK II Dynamic Mechanical Thermal Analyser working in the tensile mode. Dynamic storage modulus, $E^{\prime}$, loss modulus, $E^{\prime \prime}$, and loss tangent, $\tan \delta$, were determined. Applied frequencies were $1,3,10$, and $30 \mathrm{~Hz}$. The experiment consisted of cooling the sample with liquid nitrogen to $-140^{\circ} \mathrm{C}$ followed by heating at a rate of $1.5^{\circ} \mathrm{C} \mathrm{min}^{-1}$ up to $130^{\circ} \mathrm{C}$. The activation energies were calculated according to an Arrhenius equation from the temperature of the maximum values of the loss modulus and $\tan \delta$ at different frequencies.

\section{Microhardness}

The imprint in the material as a result of penetrating it with an indentor was measured at room temperature. A Vickers microhardness device ( $\mathrm{mhp}-160$ at a microscope UN-2) was used. The indentor is a regular square diamond pyramid, with top angle $136^{\circ}$. Loads between $1.25 \div 160 \mathrm{~g}$ were used. The thickness of the samples is $2 \mathrm{~mm}$, which guarantees no influence of the substrate hardness.

Three microhardness characteristics were used for characterizing the samples at room temperature:

1. Mayer's lines, which are the logarithmic expression of the Mayer's power law:

$$
\log P=\log a+n \log d,
$$

where $P$ is the applied load, $d$ is projected diagonal length of indentation, $a$ and $n$ are physical parameters corresponding to strength and plastic properties, respectively. When $n<2$ or $n>2$ it also means that Vickers microhardness is not uniform and decreases or

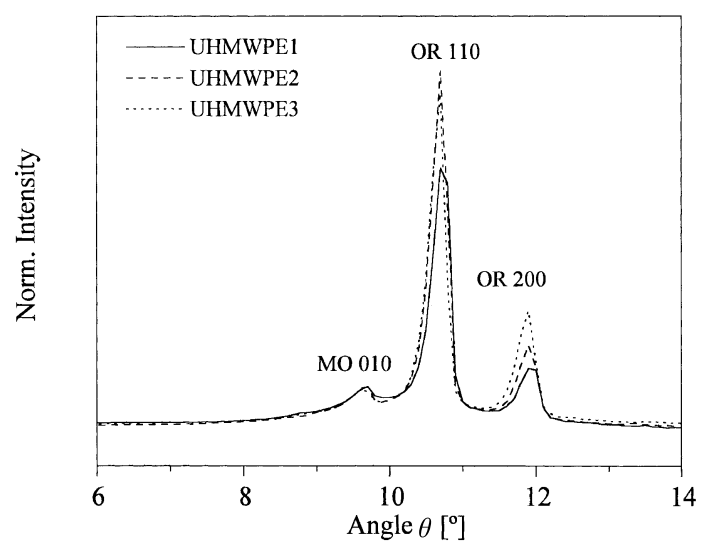

Figure 1. Wide-angle X-Ray diffraction patterns of UHMWPE samples. The diffractograms were normalized to the same total intensity.

increases, respectively, along the depth of the sample as a consequence of changing the material structure. If $n=2$ Vickers microhardness is approximately constant along the depth.

2. Vickers microhardness $(M H V)$ is a physical value characterizing the local plastic material resistance against pyramid penetration. It is connected with the irreversible component of the deformation and is calculated according to the equation:

$$
M H V=K P / d^{2}
$$

where $d$ is the projected diagonal length of the imprint after releasing the indentor and $K$ is a constant depending on the geometry of the pyramid.

3. Total microhardness $(M H T)^{20}$ which is connected with the total deformation, includes elastic, plastic and viscoelastic components. It is given by a similar equation:

$$
M H T=K P / D^{2}
$$

where $D$ is the projected diagonal length of the indentation in the loaded state. Thus defined this value can be considered as a measure for the total material resistance against the penetration of the indentor.

\section{RESULTS AND DISCUSSION}

\section{WAXS Measurements}

The X-Ray patterns in transmission modes of the three samples are shown in Figure 1. Besides the typical 110 and 200 reflections of the orthorhombic cell (OR 110 and OR 200), another reflection at about $\theta=9.6^{\circ}$ can be observed, which is attributed to the 010 reflection of the monoclinic modification of polyethylene (MO 010). This peak is characteristic for highly oriented or crystallized under the stress samples. The transition from orthorhombic to monoclinic lattice occurs only when the vector of the stress is between the 
Table I. Catalyst used, molecular weight and degree of crystallinity for the tree samples investigated

\begin{tabular}{cccc}
\hline \multirow{2}{*}{ Sample No } & Catalyst system & $\begin{array}{c}\text { Mol. weight } M_{\eta} \\
\times 10^{6}\end{array}$ & \begin{tabular}{c} 
Degree of crystall. $f_{\text {X-ray }}$ \\
\cline { 4 - 4 }
\end{tabular} \\
\hline 1 & $\mathrm{~V} / \mathrm{SiO}_{2}$ & 5.4 & 60 \\
2 & $\mathrm{Ti} / \mathrm{SiO}_{2}$ & 2.1 & 66 \\
3 & $\mathrm{Ti} / \mathrm{SiO}_{2}$ & 1.0 & 72 \\
\hline
\end{tabular}

axes $b$ and 110 , therefore the existence of a monoclinic phase in non-stressed samples of UHMWPE is unusual.

The study of the polymerization kinetics shows a relatively higher activity of the titanium catalytic systems. ${ }^{19}$ These catalysts have not good mechanical stability and during polymerization show a tendency to mechanical destruction. It was established that under the condition of heterogeneous ionic coordinated polymerization, with highly activated catalytic systems, the tie molecules enter into the lamella and physical entanglements in the amorphous areas are higher. This fact induces inner stresses in the crystals, which provoke the occurrence of the monoclinic phase. This is the most probable explanation, reported by Velikova and Damianov, ${ }^{19}$ for clearing up the reason that a bigger quantity of physical entanglements and therefore monoclinic phase occurs in the samples prepared with Ti catalytic systems. ${ }^{19}$ Moreover, the vanadium catalyst give also the monoclinic phase together with the orthorhombic phase.

The analysis of these diffractograms by subtracting the amorphous component leads to following values for the total degree of crystallinity, $f_{\mathrm{X} \text {-ray: }} 60 \%, 66 \%$ and $72 \%$ for samples 1,2 and 3 respectively (with an estimated error of about 7 units in percentage). It follows, therefore, that decreasing the molecular weight increases the crystallinity, as expected.

Regarding the proportion of monoclinic and orthorhombic crystals, it has to be considered that other monoclinic reflections (MO 200 and MO 210) are reported to overlap with the main orthorhombic peaks. ${ }^{10,11}$ It follows from Figure 1 that the intensity of the MO 010 reflection is approximately the same in the three samples, comprising around 3\% in the total diffraction area. The monoclinic crystallinity is estimated to be, therefore, of a $10 \%$ of the area, when considering the eventual contribution of the other two monoclinic peaks. Nevertheless, and considering only the equal intensities of MO 010, it could not be assured that the monoclinic content is the same in the three samples since the relative intensities between the eventual monoclinic diffractions can change among the samples as it happens with the ratio of intensities between the two orthorhombic diffractions: the relation OR 110/OR 200 is clearly decreasing on passing from sample 1 to sample 3.

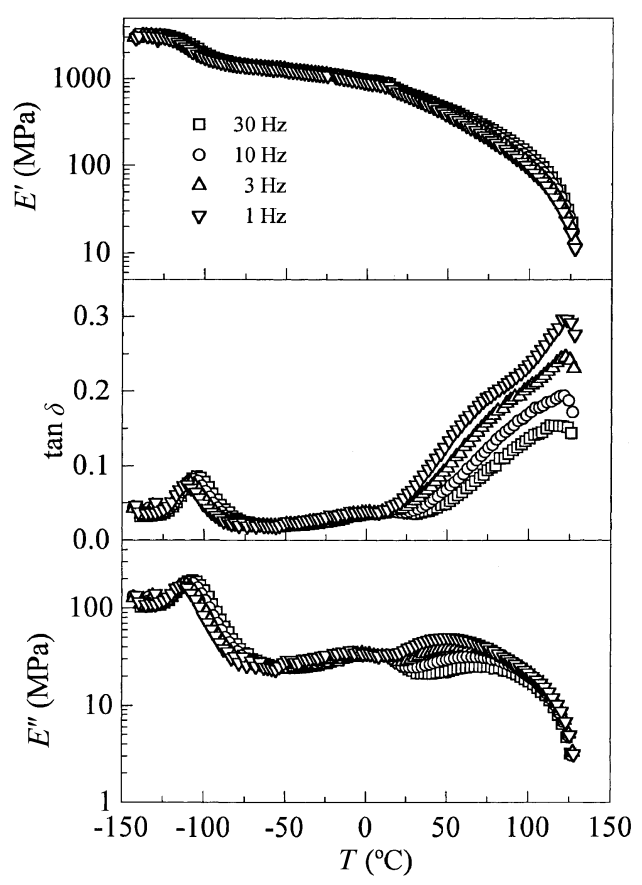

Figure 2. Temperature dependences of $E^{\prime}, E^{\prime \prime}$ and $\tan \delta$ for UHMWPE sample 1 measured at the frequencies indicated.

\section{DMTA Measurements}

Figure 2 shows the dynamic mechanical behaviour of sample 1. This sample presents two well-expressed relaxations, $\alpha$ and $\gamma$, and a very weak $\beta$ relaxation.

The $\alpha$ relaxation maximum occurs at temperatures from $50^{\circ} \mathrm{C}$ to $73^{\circ} \mathrm{C}$ ( $E^{\prime \prime}$ plots) depending on the frequency. A significant feature of this sample is the presence of a small maximum at high temperature (around $125^{\circ} \mathrm{C}$ ), which indicates that a portion of polymeric segments in the crystal phase begins to melt at that temperature.

The $\gamma$ relaxation occurs in the temperature interval from $-114^{\circ} \mathrm{C}$ to $-107^{\circ} \mathrm{C}$, obtained from $E^{\prime \prime}$ plots. This low temperature relaxation was firstly shown from Flocke $^{21,22}$ and is usually connected with the motion of polymethylene segments in amorphous areas which provokes kink formation, inversion and migration ${ }^{23}$ or crankshaft motion, requiring a minimum of tree methylene units. ${ }^{24-26}$ The temperature location of $\gamma$ relaxation is considered from some authors as the glass transition temperature for unbranched polyethylenes. ${ }^{27-29}$

Sample 1 is the only specimen that shows a weak $\beta$ relaxation. The $\beta$ relaxation occurs between $-5^{\circ} \mathrm{C}$ and $-50^{\circ} \mathrm{C}$ depending upon the type of polyethylene. ${ }^{30-33}$ 
Table II. Values of the activation energy $\left(\mathrm{kJ} \mathrm{mol}^{-1}\right)$ and temperature location of the corresponding relaxations obtained for the three UHMWPE samples from $E^{\prime \prime}$ and $\tan \delta$ plots at a frequency of $3 \mathrm{~Hz}$

\begin{tabular}{|c|c|c|c|c|c|c|c|c|c|c|}
\hline \multirow{3}{*}{$\begin{array}{c}\text { Sample } \\
\text { No }\end{array}$} & \multicolumn{3}{|c|}{$\Delta H\left(E^{\prime \prime}\right.$ plot $)$} & \multicolumn{2}{|c|}{$\Delta H(\tan \delta$ plot $)$} & \multicolumn{3}{|c|}{$T\left({ }^{\circ} \mathrm{C}\right)\left(E^{\prime \prime}\right.$ plot $)$} & \multicolumn{2}{|c|}{$T\left({ }^{\circ} \mathrm{C}\right)(\tan \delta$ plot } \\
\hline & $\gamma$ & $\beta$ & $\alpha$ & $\gamma$ & $\beta$ & $\gamma$ & $\beta$ & $\alpha$ & $\gamma$ & $\beta$ \\
\hline & \multicolumn{3}{|c|}{ Relaxations } & \multicolumn{2}{|c|}{ Relaxations } & \multicolumn{3}{|c|}{ Relaxations } & \multicolumn{2}{|c|}{ Relaxations } \\
\hline 1 & 107 & $95^{\mathrm{a}}$ & 114 & 111 & $77^{\mathrm{a}}$ & -111 & $-4^{\mathrm{a}}$ & 58 & -109 & $1^{\mathrm{a}}$ \\
\hline 2 & 106 & & 127 & 110 & & -113 & & 57 & -110 & \\
\hline 3 & 107 & & 141 & 102 & & -111 & & 58 & -109 & \\
\hline
\end{tabular}

The origin of the $\beta$ relaxation is still unresolved but is commonly attributed to the amorphous phase. This relaxation occurs when there are branches, as for example LDPE and LLDPE, but it sometimes appears, though weakly, in some samples of linear polyethylenes. Some authors have concluded that the $\beta$ relaxation results from motions of chain units in the interfacial region ${ }^{30}$ whereas some others attributed this process to the glass transition. ${ }^{31,32}$ A recent paper ${ }^{33}$ has suggested a different molecular origin of the $\beta$ relaxation in linear polyethylene with high molecular weights quite dissimilar to those aforementioned for branched polyethylene. Because of the formation of loose tie and loop molecules in the amorphous layers in polyethylene with high molecular weights, the $\beta$ relaxation seems to be a consequence of the motion of the loose tie molecules in this type of polyethylene. The absence of the $\beta$ relaxation in typical linear polyethylene having a thinner amorphous layer thickness, which is considered to promote taut tie molecules, can be directly attributed to the lack of loose tie molecules. ${ }^{33}$ In the current work, sample 1 has the highest molecular weight and, consequently, its loose tie molecular fraction should be also the highest one, showing, accordingly, a weak $\beta$ relaxation.

There is an important error in determining the activation energy value of the $\beta$ relaxation because it has a very flat shape and practically there is a plateau in a large temperature interval instead a maximum. Taking into account the uncertainty of the activation energy values of the $\beta$ relaxation listed in Table II, they lie in a range similar to that of a linear polyethylene $\left(M_{\mathrm{w}}=1.42 \times 10^{6}\right)$ quoted in ref 33 .

Figure 3 compares the variation of $E^{\prime}, E^{\prime \prime}$ and tan $\delta$ as a function of temperature, measured at frequency $3 \mathrm{~Hz}$, for the three samples studied. The $\alpha$ relaxation is well expressed as a maximum in the dependence $E^{\prime \prime}$ vs. $T$ and as a small hump before the melting process in the temperature dependence of $\tan \delta$. The intensity of this relaxation ( $E^{\prime \prime}$ basis) increases in the order samples of $1,2,3$, which signifies that the degree of crystallinity increases in this order. This relaxation does not changes its temperature position $\left(58^{\circ} \mathrm{C}\right)$ indicating that the lamella thickness remains constant. ${ }^{34}$

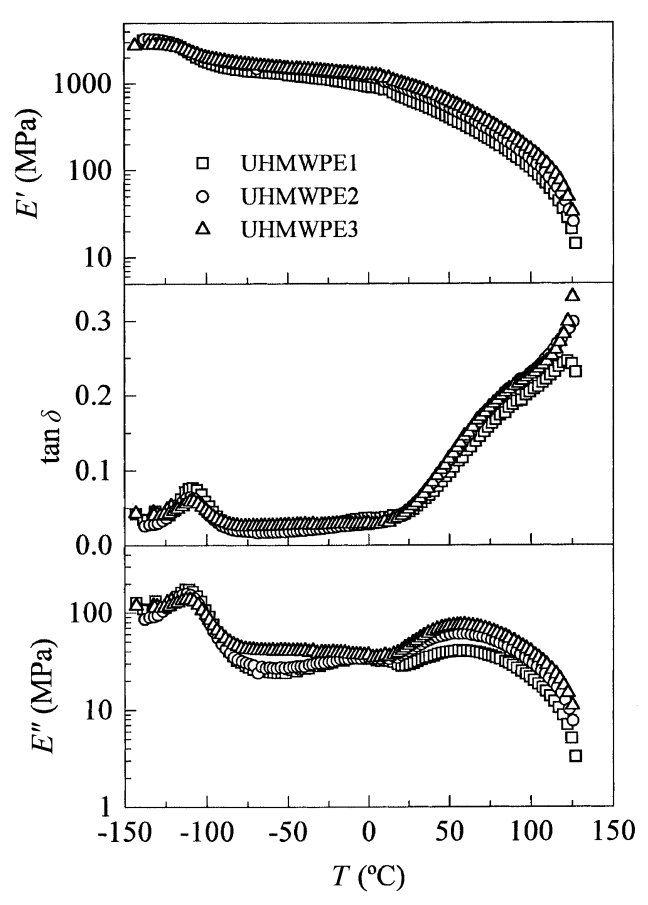

Figure 3. Comparison of the temperature dependences of $E^{\prime}$, $E^{\prime \prime}$ and $\tan \delta$ as a function of the temperature, measured at $3 \mathrm{~Hz}$, for the three samples studied.

Moreover, the value of the activation energy $(\Delta H)$ for the $\alpha$ relaxation increases in the order of samples 1,2 , and 3 because of increasing the degree of crystallinity. Similar values are found in the literature. ${ }^{32,35,36}$ The increase of the crystallinity is reflected also in the increase of the storage modulus $E^{\prime}$ and the decrease of the intensity of the $\gamma$ relaxation, associated to the amorphous phase. This effect could be also attributed to the increasing quantity of the physical entanglements and tie molecules. Moreover, the influence of both structural changes (degree of crystallinity and quantity of the physical entanglements and tie molecules) on the dynamic mechanical behaviour could not be distinguished because they act in the same way.

The intensity of the $\gamma$ relaxation usually is associated with the amorphous region of the semicrystalline polymers. Therefore, the increase of the intensity of the $\gamma$ relaxation in the order of samples 3,2,1 can be attributed to the increase of the quantity of the amorphous phase. Though a lot of work concerning the $\gamma$ relaxation in polyethylene has been done, there is no clear 
Table III. Vickers and Total microhardnesses determined for a load of $40 \mathrm{~g}$, microhardness of the crystal phase $\left(M H V_{\mathrm{c}}\right)$ calculated by the parallel model ${ }^{38}$ and values of the parameter $n$ obtained from Mayer's lines

\begin{tabular}{|c|c|c|c|c|}
\hline $\begin{array}{c}\text { Sample } \\
\text { No }\end{array}$ & $\frac{M H V}{\mathrm{MPa}}$ & $\frac{M H T}{\mathrm{MPa}}$ & $\frac{M H V_{c}}{\mathrm{MPa}}$ & $n$ \\
\hline 1 & 32.6 & 20.7 & 63.9 & 2.038 \\
\hline 2 & 37.2 & 23.1 & 64.7 & 2.037 \\
\hline 3 & 41.1 & 27.6 & 66.2 & 2.060 \\
\hline
\end{tabular}

consensus regarding the details of the underlying motional process. However a body of opinions holds that it occurs predominantly in the amorphous phase but also includes the loose chain ends in the crystals as well as in the amorphous fraction. Moreover, in this work location of the $\gamma$ relaxation dose not change with the content of crystallinity because the range of crystallinities is small and does not influence the $\gamma$ relaxation temperature. In previous works ${ }^{32,35,36}$ it was found that the position of $\gamma$ loss modulus peak can change between $-125^{\circ} \mathrm{C}$ and $-105^{\circ} \mathrm{C}$ depending of the type of polyethylene (LDPE, LLDPE or HDPE) and therefore of the content of crystallinity (between $20 \%$ and $70 \%$ ).

At temperatures below the $\gamma$ relaxation storage modulus $E^{\prime}$ of sample 3 becomes smaller than the other two. One possible explanation of this fact could be that below that relaxation the modulus of elasticity of the amorphous phase is higher than that of the crystal one. This sample has the smallest quantity of amorphous phase and moreover the physical cross-linking now could not contribute to the increasing of the storage modulus. Besides, this sample has the lowest molecular weight and it is know that the stiffness of the polyethylene, although primarily influenced by density, also increases slightly with molecular weight. ${ }^{37}$

The values of the activation energy $(\Delta H)$ of the $\gamma$ relaxation change between 60 and $125 \mathrm{~kJ} \mathrm{~mol}^{-1}$ for the different kinds of polyethylenes. ${ }^{32,35,37}$ In the Table II are shown the $\Delta H$ values obtained for the three samples from $E^{\prime \prime}$ and $\tan \delta$ plots. It could be seen that $\gamma$ relaxation has almost the same $\Delta H$ value, i.e., the releasing of the movement in amorphous phase is not influenced by the presence of entanglements and tie molecules.

Finally, there is not any influence of the content of monoclinic phase in the position and intensity of the different relaxations.

\section{Microhardness Measurements}

$M H V$ and $M H T$, determined for a load of $40 \mathrm{~g}$, the values of the parameter $n$ and the microhardness of the crystal phase $\left(M H V_{\mathrm{c}}\right)$, calculated by the parallel model, ${ }^{38}$ are listed in Table III. The parameter $n$, obtained from the slope of Mayer's lines has a value around 2, which means that $M H V$ can be considered as

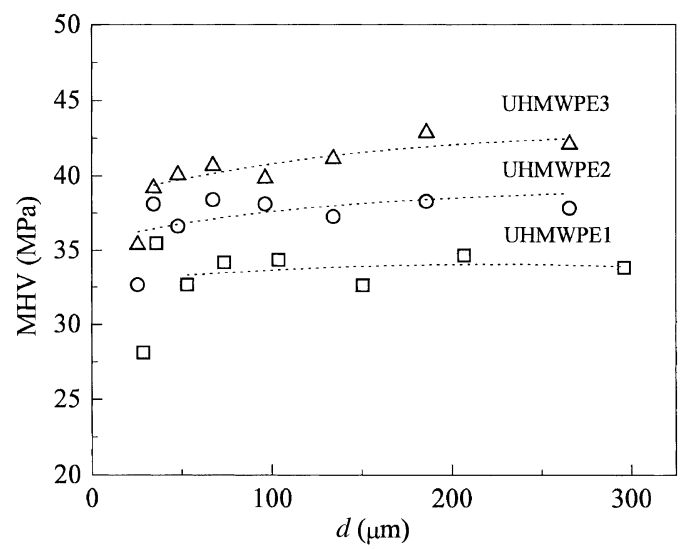

Figure 4. Dependence of Vickers microhardness as a function of diagonals of the indentation.

constant in depth.

Figure 4 illustrates $M H V$ as a function of diagonal length $d$. $M H V$ remains almost constant for $d>$ $40 \mu \mathrm{m}$, which is in accordance with the conclusions from Mayer's lines. It could be supposed that lower values of $M H V$ for small $d$ values and consequently low depths of penetration are due to the different crystallization rates or restricted crystallization conditions on the surface and in the sample bulk. It is presumable that crystal lattice in the surface is less perfect. Comparing the graphs for the three samples it could be seen that $M H V$ increases with increasing the degree of crystallinity and decreasing the molecular weight. It was established that for polyethylenes $M H V$ goes up linearly with increasing of molecular weight till values of $10^{5}$. After that $M H V$ remains almost constant, or even decreases slowly. ${ }^{39-41}$ When molecular chains become larger and larger $\left(M_{\eta}>10^{6}\right)$, they can take part in more than one lamellae, and in this way additional entanglements and tie molecules in the amorphous layers between crystallites are created. As a result, increasing of molecular weight leads to decreasing the degree of crystallinity, and lower crystalline perfection $\left(M H V_{\mathrm{c}}\right.$ decreases).

Balta-Calleja considers that the elastic deformation is mainly due to the amorphous phase. ${ }^{42}$ It was mentioned before that total microhardness $(M H T)$ is sensitive to total deformation including the elastic one. The changes of the $M H T$ values, when $M H V$ values (sensitive to plastic deformation) are constant for the same diagonal range (Figure 5 inset), can be then attributed to changes of the elastic properties and consequently to changes in the amorphous structure.

Figure 5 shows total microhardness $v s$. diagonal. For $D$ values smaller than 60-70 $\mu \mathrm{m}$ (depth of indentation about $9 \mu \mathrm{m}) M H T$ enormously increases. The reason for this effect is not very clarified by now but there are two suggestions: the indentor has not a per- 


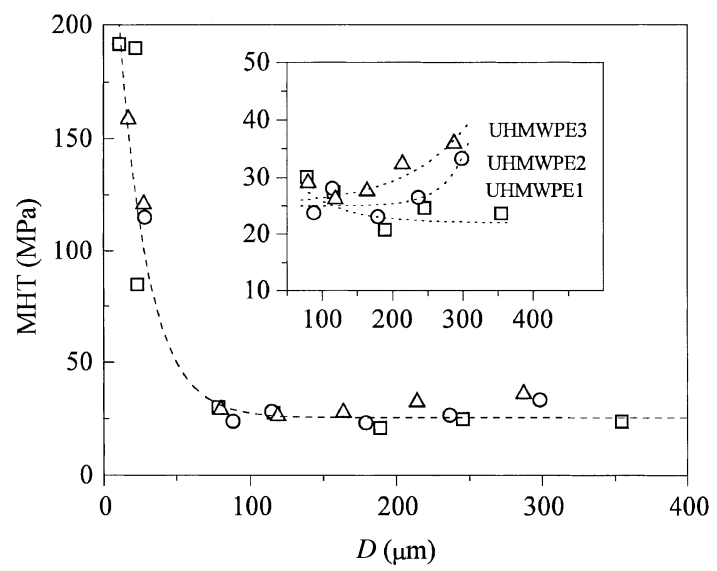

Figure 5. Dependence of Total microhardness as a function of diagonals of the indentations in the loaded state (the inset shows the same dependence for high values of the diagonal).

fect top ${ }^{43}$ and/or it is a result of the so called "scale factor". ${ }^{44}$ Moreover, for bigger depths, total microhardness slowly increases for samples 2 and $3\left(\mathrm{Ti} / \mathrm{SiO}_{2}\right.$ catalyst system) and remains almost constant for sample $1\left(\mathrm{~V} / \mathrm{SiO}_{2}\right.$ catalyst system). One possible explanation could be that in the inner layers, because of their less hindered crystallization conditions, some crystal structural improvement could take place. The additional building of the crystalline lamellae is at the expense of the molecule segments belonging to amorphous areas. So, the polymer chains in the disordered phase become more stretched.

In general, an important feature for determining the morphology of the amorphous area of the UHMWPE is the relation between rate of polymerization, rate of crystallization and stability of the catalytic particle. ${ }^{18,19}$ At low activity and high stability of the catalytic particle and relatively high crystallization rate it is possible to build crystals with longer chains and small quantity of entanglements ${ }^{18}$ (vanadium catalytic systems, sample 1). In the case of the UHMWPE obtained with titanium catalytic system (samples 2 and 3) having a low mechanical stability, polymerization rate exceeds the crystallization one and the structure of the UHMWPE is predominately lamellar with a high concentration of tie molecules and entanglements in amorphous areas. ${ }^{19}$

The decreasing of the macromolecular segments in the amorphous phase leads to an additional stretching of tie molecules and tightening of entanglements, therefore the resistance of the amorphous phase against the penetration increases. That is why $M H T$ of samples 2 and 3, with many physical entanglements, increases. A similar effect was observed in annealed UHMWPE samples. ${ }^{45}$ For sample 1, catalyzed with vanadium, $M H T$ increases negligibly, because of the relatively small amount of initial tie molecules and entanglements.

\section{CONCLUSIONS}

The catalyst system has a clear influence on the crystallinity of the samples, owing to the different molecular weights obtained. In all the cases a significant amount of monoclinic modification is observed, which is estimated to be of the order of $10 \%$. No differences in the content of monoclinic modification can be established among the samples. The differences in crystallinity and the expected ones in the density of entanglements in the amorphous phase are reflected on the DMTA results: With increasing the degree of crystallinity and the quantity of entanglements the storage modulus and the intensity of the $\alpha$ relaxation increase and the $\gamma$ relaxation decreases. A weak $\beta$ relaxation occurs only in sample 1 , obtained with vanadium catalytic systems.

Microhardness measurements give the possibility of distinguishing the effect of crystallinity from the effect of entanglements: Vickers microhardness is sensitive predominately to the crystalline phase, while total microhardness is sensitive also to the structural peculiarities in the amorphous phase. It was established also that perfection of the crystal phase increases with increasing the crystallinity.

Acknowledgments. We thank the NATO Science Committee for the invited scientist grant awarded to one of us (GZ). The support from the Bulgarian Academy of Sciences and the Spanish Council for Scientific Research (CSIC) (project 2001 BG 0003) is also gratefully acknowledged. We also thank Drs. M. Velikova and D. Damyanov from University "Prof. Dr. A. Zlatarov", Bourgas, Bulgaria for supplying the samples and one of the reviewers of the manuscript for driving our attention to ref 33 .

\section{REFERENCES}

1. C. Klapperich, K. Komvopoulos, and L. Pruitt, J. Tribol.,121, 394 (1999).

2. T. Yu. M., T. Kanamoto, K. Takahasi, and A. A. Berlin, Meh. Kompoz. Mater. (Zinatne), 2, 351 (1991).

3. S. Rastogi, L. Kurelec, and P. J. Lemstra, Macromolecules,31, 5022 (1998).

4. G. Zamfirova, J. Jeliazkov, and E. Nedkov, Colloid Polym. Sci., 260, 105 (1991).

5. S. M. Kurtz, O. K. Muratoglu, M. Evans and A. Edidin, Biomaterials, 20, 1659 (1999).

6. J. T. E. Cook, P. G. Klein, I. M. Ward, A. A. Brain, D. F. Farrar, and J. Rose, Polymer, 41, 8615 (2000).

7. M. Kresteva, E. Nedkov, and M. Mihailov, Bulg. J. Phys., 6, 667 (1979). 
8. W.-G. Hu and K. Schmidt-Rohr, Polymer, 41, 2979 (2000).

9. Y.-L. Hsieh and X.-P. Hu, J. Polym. Sci., Part B: Polym. Phys., 35, 623 (1997).

10. D. L. Vander Hart and F. Khoury, Polymer, 25, 1589 (1984).

11. Y. Takahashi and T. Ishida, J. Polym. Sci., Part B: Polym. Phys., 26, 2267 (1988).

12. L. Kurelec, S. Rastogi, R. J. Meier, and P. J. Lemstra, Macromolecules, 33, 559 (2000).

13. H. J. Kestenbach and J. Petermann, Polymer, 35, 5217 (1994).

14. B. L. Timas and S. L. Sass, Makromol. Chem., 164, 333 (1977)

15. J. Preedy and E. Wheeler, Makromol. Chem., 178, 2461 (1977).

16. J. Pennings and A. Zwijenberg, J. Polym. Sci., 17, 1011 (1978).

17. M. Misheva, N. Djourelov, G. Zamfirova, and A. Dimitrova, Macromol. Chem. Phys., 17, 2348 (2000).

18. M. Velikova, L. Minkova, D. Damyanov, and S. Rangelov, Eur. Polym. J., 33, 403 (1997).

19. M. Velikova and D. Damyanov, Polym. Bull., 44, 203 (2000).

20. G. Zamfirova and A. Dimitrova, Polym. Test., 19, 533 (2000).

21. H. A. Flocke, Kolloid Z. Z. Polym., 180, 118 (1962).

22. R. E. Wetton, 'Dynamic Mechanical Thermal Analysis of Polymers and Related Systems' in "Developments in Polymer Characterization", J. V. Dawkins, Ed., Elsevier Applied Science Pub., London, 1986, chapt. 5, pp 179-221.

23. N. J. Heaton, R. Benavente, E. Pérez, A. Bello, and J. M. Pereña, Polymer, 37, 3791 (1996).

24. T. F. Schatzki, J. Polym. Sci., 57, 496 (1962).

25. R. F. Boyer, Rubber Chem. Technol., 34, 1303 (1963).

26. J. M. Pereña, Revista de Plásticos Modernos, 350, 167 (1985).

27. F. C. Stehling and L. Mandelkern, Macromolecules, 3, 242 (1970).

28. J. M. Pereña and J. M. G. Fatou, An. Fis., 68, 207 (1972).
29. H. Lee, K. Cho, T-K. Ahn, S. Choe, I.-J Kim, I. Park, and B. H. Lee, J. Polym. Sci., Part B: Polym. Phys., 35, 1633 (1997).

30. R. Popli, M. Glotin, L. Mandelkern, and R. S. Benson, J. Polym. Sci., Polym. Phys. Ed., 22, 407 (1984).

31. Y. Jin and R. H. Boyd, J. Chem. Phys., 108, 9912 (1998).

32. M. L. Cerrada, R. Benavente, and E. Pérez, Macromol. Chem. Phys., 202, 2686 (2001).

33. K.-H. Nitta and A. Tanaka, Polymer, 42, 1219 (2001).

34. E. Laredo, N. Suarez, A. Bello, B. Rojas, M. A. Gomez, and J. M. G. Fatou, Polymer, 40, 6405 (1999).

35. M. L. Cerrada, R. Benavente, B. Peña, and E. Pérez,, Polymer, 41, 5957 (2000).

36. M. L. Cerrada, R. Benavente, E. Pérez, and J. M. Pereña, J. Polym. Sci., Part B: Polym. Phys., 39, 1 (2001).

37. Y. P. Kahanna, E. A. Turi, T. J. Taylor, V. V. Vickroy, and F. Abbott, Macromolecules, 18, 1302 (1985).

38. F. J. Baltá-Calleja, J. M. Salazar, and H. Cackovic, J. Mater. Sci., 16, 275 (1981).

39. F. J. Baltá-Calleja, C. Santa Cruz, R. K. Bayer, and H. G. Kilian, Colloid Polym. Sci., 268, 440 (1990).

40. F. J. Baltá-Calleja, L. Giri, I. M. Ward, and D. L. M. Cansfield, J. Mater. Sci., 30, 1139 (1995).

41. R. K. Bayer, F. J. Baltá-Calleja, E. López Cabarcos, H. G. Zachmann, A. Paulsen, F. Bruening, and W. Meins, J. Mater. Sci., 24, 2643 (1989).

42. F. J. Baltá-Calleja, Adv. Polym. Sci., 66, 117 (1985).

43. V. Lorenzo, Ph. D. Thesis in Engineering, Technical University of Madrid, 1987.

44. S. I. Bulychev and B. P. Alehin, "Ispitanie Materialov Nepereryvnym Vdalivaniem Indentora", Mashinostroenie, Moskva, 1990, ISBN 5-217-00842-3.

45. M. Kresteva, E. Nedkov, and A. Radilova, Colloid Polym. Sci., 263, 273 (1985). 